\title{
QUILES, F., QUIÑNONES, A., CRUZ, C. Y PADILLA, C. (EDS.). COMO BÁLSAMO DE FIERABRÁS. CULTURA EN TIEMPOS Y TERRITORIOS EN CONFLICTO. SEVILLA: UNIVERSIDAD PABLO DE OLAVIDE, 2018
}

Andrés Mora Ramírez

Recibido: 25/05/19 - Aceptado: 30/05/19

Desde finales del siglo XX, distintas investigaciones académicas, organismos internacionales e informes de organizaciones de la sociedad civil coinciden en caracterizar a América Latina y el Caribe como la región más desigual del mundo, por encima incluso del África Subsahariana. Una desigualdad que trasciende el ámbito estrictamente asociado a la distribución de los ingresos generados por las economías nacionales entre hogares y personas, porque incide negativamente en las posibilidades de realización de derechos humanos fundamentales -económicos, sociales y culturales- de millones de habitantes de nuestros países. Como lo señala CEPAL en su Panorama social de América Latina 2018, "los altos niveles de desigualdad traban el desarrollo y son una barrera a la erradicación de la pobreza, la ampliación de la ciudadanía, el ejercicio de los derechos y la gobernabilidad democrática" (17).

En esta misma línea de aproximaciones a la realidad latinoamericana y caribeña, a nuestra compleja cartografía de problemas sociales y humanos, en sentido amplio, conviene hacer referencia a dos datos más: en el año 2009, el Programa de Naciones Unidas para el Desarrollo caracterizó a Centroamérica, y en concreto al llamado Triángulo Norte-Guatemala, El Salvador y Honduras-, como la región más violenta del mundo, en la que se presentaban las tasas más altas de homicidio para territorios donde no existen conflictos armados o guerras formalmente declaradas (19). Por su parte, en Colombia, en el 2018, y después de un proceso de diálogo de poco más de seis años, representantes del gobierno y las Fuerzas Armadas Revolucionarias de Colombia (FARC) firmaron un acuerdo de paz que puso fin, parcialmente, a un doloroso conflicto que se instaló en la sociedad colombiana desde hace más de medio siglo y que, de acuerdo con distintas fuentes, dejó más de 262 mil muertos -entre civiles y combatientes- (Centro Nacional de Memoria Histórica) y más de 7 millones de desplazados desde 1985 (ACNUR).

En este delicado contexto, fue publicado el año anterior el libro Como bálsamo de Fierabrás. Cultura en tiempos y territorios en conflicto, un esfuerzo colectivo de 
investigadores y artistas europeos, centroamericanos y colombianos, auspiciado por el programa Aula Latinoamericana de Pensamiento y Creación Contemporáneos, de la Universidad Pablo de Olavide de Sevilla, España.

Con la evocación de un conocido pasaje de la novela Don Quijote de la Mancha, las y los autores del libro emprenden un empeño quijotesco que desarrollan a lo largo de los veintisiete capítulos que conforman la obra, y que puede sintetizarse así: construir una visión panorámica de las dinámicas culturales en Centroamérica y Colombia en el siglo XXI, con especial interés en las influencias que ejercen, sobre colectivos y territorios, los fenómenos asociados a las distintas expresiones de conflictividad social y violencia en esta amplia región. Violencias y conflictos de carácter histórico y estructural, como las que afectan particularmente a los pueblos indígenas, sus territorios y culturas; y otras formas de violencia acentuadas por el neoliberalismo dominante en las políticas públicas y en el perfilamiento del sentido común de nuestras sociedades.

La intencionalidad del libro es clara: ir al encuentro de las experiencias de promoción y gestión cultural, allí donde las violencias se han impuesto como patrón de cotidianeidad en las comunidades, y donde la cultura deviene ámbito de la resistencia, la creatividad, la búsqueda de alternativas y, sobre todo, de construcción de la paz. Como bien lo puntualiza uno de los editores, Fernando Quiles, "en innumerables ocasiones se ha podido calmar, si no curar, el dolor de la memoria con la aplicación de un bálsamo artístico" (13).

Carmen Cruz, otra de las editoras, lanza desde Honduras una pregunta retórica que interpela al lector: "si vivimos en guerra, y si la inseguridad es nuestro pan de cada día, y si la violencia en diferentes expresiones impera en nuestra sociedad, ¿qué papel juega "la cultura" en medio de esta grave situación que nos acecha?" (23). La respuesta que ensaya en su capítulo titulado Violencia y cultura en el Triángulo Norte de Centroamérica enhebra en la aguja narrativa el hilo conductor del conjunto de la obra: corresponde a la cultura, como campo de producción de sentido y significación sobre la existencia individual y colectiva, y a las y los artistas, como creadores y mediadores de ese proceso, traducir el dolor de los pueblos en esperanza:

La cultura es la que tiene que y puede transformar y construir las nuevas ciudadanias de la paz, entendiendo que desde el arte se puede construir, se pueden alimentar y se pueden fortalecer ciudadanías creativas, libres, con perspectiva de futuro, capaces de transformarse a sí mismas y entender desde una perspectiva más amplia el contexto en el que viven (24).

Organizado en tres ejes temáticos generales, el libro integra los aportes de investigadores, artistas y gestores culturales de Guatemala, Honduras, El Salvador, Nicaragua, Costa Rica, Colombia, España y Francia, configurando así una perspectiva amplia, intercultural e interdisciplinaria sobre el objeto de estudio. En la primera parte, Culturas, territorios y reconocimiento, se analizan distintas prácticas de resistencia 
cultural de los pueblos indígenas salvadoreños, relacionadas con la salvaguarda y revitalización lingüística por la vía de la promoción de políticas culturales orientadas bajo el principio de justicia social (tales los casos de los textos de Werner Hernández y Quentin Boitel). Destaca, asimismo, la contribución de Ana Quiñones sobre las movilizaciones de la sociedad civil colombiana durante las negociaciones de los acuerdos de paz entre el gobierno del presidente Juan Manuel Santos y las FARC: desde otro punto geográfico de América Latina, el contrapunto de este texto con la realidad centroamericana y su proceso de paz todavía inconcluso, permite al lector acercarse a otras trayectorias de lucha y a formas de acción política no violenta, en un escenario en el que la violencia recorre transversalmente el entramado social y condiciona, en buena medida, el horizonte de esperanza del pueblo colombiano.

En la segunda parte, Conflictos, educación e integración, las prácticas artísticas y educativas formales e informales adquieren protagonismo en el análisis de la dinámica cultural centroamericana, por su valor como recurso para promover la recuperación de la memoria colectiva, para reconstituir los vínculos sociales y los espacios de comunidad rotos por las violencias, y por supuesto, por su valor formativo en la construcción de una nueva ciudadanía capaz de abrir nuevas rutas hacia la paz y el desarrollo humano. Vale recordar aquí las palabras del periodista Paolo Luers, en su sistematización de la experiencia del Teatro del Azoro en la cárcel de Ciudad Barrios en San Salvador, durante la tregua entre pandillas del año 2013: "tampoco hay que olvidarse que la cultura y el arte, por más poderosas que pueden ser como hechos simbólicos, no van a construir paz, si a la par no van inversiones 'reales' en la transformación de los territorios marginados. 'Circo y Pan' puede ser una estrategia vigente, pero circo sin pan jamás" (209).

Finalmente, la tercera parte, Patrimonio y artes ante los conflictos, centra su atención en el potencial emancipador del arte frente a la fuerza de la colonialidad que se ejerce sobre los cuerpos femeninos, sobre las culturas e identidades diversas -como la queer-, así como sus aportes sanadores en los procesos de reconciliación posconflicto armado. Las tensiones que provoca esa colonialidad tanto en Centroamérica como en Colombia, permiten seguir el rastro de las múltiples violencias que hieren a nuestra región y a los grupos más vulnerables de la población.

Propio de toda obra coral, este libro transita por los caminos del riesgo que supone convocar la diversidad de estilos, procesos de escritura, miradas y acentos de sus autores y autoras; recorrido no exento de altibajos, pero que cumple sus objetivos al articular andamios de coherencia en el armado de los distintos temas y capítulos. En ello cabe un justo reconocimiento al trabajo de sus editores.

Como bálsamo de Fierabrás. Cultura en tiempos y territorios en conflicto, se convierte así en un texto de referencia para investigadores sociales y gestores culturales, interesados en profundizar en el estudio de experiencias de resistencia y construcción de políticas culturales alternativas en una época como la nuestra, marcada por las 
múltiples formas de violencias y exclusiones, desgarramientos del tejido social y fracturas democráticas, sobre las que se asienta el triunfo -incuestionable, por ahora- del proyecto hegemónico neoliberal en Centroamérica y más allá del istmo.

\section{Bibliografía}

ACNUR. Hay más víctimas de desplazamiento forzado en Colombia que número de habitantes en Costa Rica. Alto Comisionado de las Naciones Unidas para los Refugiados. Recuperado de https://www.acnur.org/noticias/noticia/2018/12/5c243ef94/hay-mas-victimas-dedesplazamiento-forzado-en-colombia-que-numero-de-habitantes.html

Centro Nacional de Memoria Histórica. 262.197 muertos dejó el conflicto armado. Centro Nacional de Memoria Histórica de Colombia. Recuperado de http://www.centrodememoriahistorica.gov.co/noticias/noticias-cmh/262-197-muertos-dejo-el-conflicto-armado

CEPAL. Panorama social de América Latina 2018. Recuperado de https://repositorio.cepal.org/ bitstream/handle/11362/44395/11/S1900051_es.pdf

PNUD. Informe sobre desarrollo humano para América Central 2009-2010. Recuperado de https:// www.undp.org/content/dam/rblac/docs/Research\%20and\%20Publications/Central_ America_RHDR_2009-10_ES.pdf

Andrés Mora Ramírez. Costarricense. Tiene una Maestría en Estudios Latinoamericanos con énfasis en Cultura y Desarrollo, y una Maestría en Educación con énfasis en Docencia Universitaria, ambas de la Universidad Nacional de Costa Rica (UNA). Es profesor e investigador del Instituto de Estudios Latinoamericanos de la UNA, donde participa en el proyecto Hacia el 200 aniversario de la independencia: Centroamérica vista desde distintas geografías, perspectivas socio-politicas y momentos históricos. Actualmente se desempeña como coordinador de la Maestría en Estudios Latinoamericanos y del Programa Repertorio Americano de dicho instituto. Es miembro de los grupos de trabajo de CLACSO: "El istmo centroamericano repensando los centros: narrativas, subjetividades y geopolíticas" y "Geopolítica, sistema mundial e integración regional".

Correo: andres.mora.ramirez@una.ac.cr

ORCID: 0000-0001-9476-3233 